\title{
UNA LECTURA DE LA ANTROPOLOGÍA BORGIANA: LAS OVEJAS DE CÉSAR AIRA
}

\author{
A READING OF BORGIAN ANTHROPOLOGY: \\ LAS OVEJAS BY CÉSAR AIRA
}

RAfael Arce

Universidad Nacional del Litoral / CONICET

rafael.arce@gmail.com

Recibido: 11.05 .2021

Aceptado: 18.09.2021

\begin{abstract}
RESUMEN: Este trabajo propone una lectura de la primera novela de César Aira, Las ovejas, escrita en 1970 y publicada en 1984. Para ello, se atiende la relación de este texto con la obra de Jorge Luis Borges, partiendo de una conjetura genealógica que el mismo Aira sugiere. En esta genealogía, la animalidad cumple un papel determinante que explica el recorte intertextual del desenlace de la novela. Nuestra hipótesis afirma que es posible leer Las ovejas como una versión de la "antropología borgiana", tal como la denominó Jaime Rest. En esta versión, la novela de Aira desplaza el presupuesto humanista del idealismo de Borges. Esta conjetura permite revisar el "vitalismo" de la obra de Aira y pensarlo, no en clave de "darwinismo", como ha sido leído, sino en relación con la obra de Samuel Butler. Finalmente, esta lectura propone replantear los términos en los que se ha pensado la poética del olvido en Aira.
\end{abstract}

PALABRAS CLAVE: Idealismo, vida, animalidad, Vanguardia, novela

ABSTRACT: This work proposes a reading of César Aira's first novel, Las ovejas, written in 1970 and published in 1984. For this, we consider the relationship of this text with the work of Jorge Luis Borges, beginning from a genealogical conjecture that Aira himself suggests. In this genealogy, animality plays a determining role that explains the intertextual cut of the novel's denouement. Our hypothesis is that it is possible to read Las ovejas as a version of the "anthropology of Borges", as Jaime Rest called it. In this version, Aira's novel displaces the humanistic presupposition of Borges's idealism. This conjecture allows us to review the "vitalism" of Aira's work 
and to think about it, not in terms of "Darwinism", as has been read, but in relation to the work of Samuel Butler. Finally, this reading proposes to rethink the terms in which the poetics of oblivion has been thought in Aira.

KeYWorDS: Idealism, Life, Animality, Vanguard, Novel

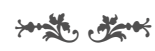

Las ovejas es la primera novela que escribió César Aira. Al menos, eso nos dice la mitología que el escritor ha forjado en torno de su obra. Después de cuatro décadas y más de cien relatos, Aira no abandona su costumbre de fechar el texto al pie de la última página, de modo que el crítico que aborda su obra dispone de dos fechas, la de escritura y la de publicación. En las últimas dos décadas, su creciente consagración ha restado importancia a esta duplicidad, puesto que publica con regularidad y las fechas solo expresan el delay normal entre escribir y publicar. No obstante, esta duplicidad resulta más interesante a medida que nos remontamos a los orígenes. Aira empieza a escribir en la década del 70, pero su primer libro, Ema, la cautiva, se publica en 1982. Además, Moreira, fechado en 1972, y cuyo pie de imprenta indica 1975, no salió ese año, por un problema con las tapas, sino a fines de 1982, de modo que si se atiende a los pies de imprenta se trataría de su primer libro publicado, pero que en realidad vio la luz poco después de Ema. Este avatar es uno de los tantos que sufrió Aira en sus inicios, tal como nos lo cuenta Ricardo Strafacce en su biografía de Osvaldo Lamborghini (2008: 305-313). El mismo Aira noveló el incidente en La vida nueva (2007).

Hoy puede sorprender los problemas que Aira tuvo en sus inicios para publicar. No obstante, la novedad de su literatura, disimulada en estos tiempos por su consagración y estabilización teórica-crítica, encontró entonces no pocas resistencias. Strafacce enumera una serie de novelas que Aira escribió en los 70 y que hasta hoy permanecen inéditas: Individual, Pensacola, Los cuatreros, Un puente, un gran puente, Danae, Zilio y El estúpido reflejo de la manzana en la ventana (2008: 459 y 562). De Zilio, Strafacce reproduce un fragmento y El estúpido reflejo de la manzana en la ventana aparece mencionada en Las hijas de Hegel de Lamborghini (2013: 235). El lugar común crítico acerca de que Aira publica absolutamente todo, sin hacer caso a la calidad de sus textos, encuentra en esta circunstancia un cuestionamiento atendible.

En su libro pionero, Sandra Contreras se refiere a esta duplicidad de las fechas y conjetura que la constancia al final de cada texto alude a una especie de datación propia del diario de escritor, lo que conectaría con una suerte de autobiografía que constituirían el conjunto de novelas y relatos. Contreras prefiere, para su lectura de la obra, los años de escritura (2002: 34). Las ovejas, fechado en 1970, se publicó en 1984 junto con El vestido rosa. A pesar de la reedición que Random House Mondadori ha venido haciendo de los relatos de Aira, ni Moreira (Achával Solo Editor, 1975) ni El vestido rosa-Las ovejas (Ada Korn Editora, 1984) 
han vuelto a publicarse, lo que convierte a estos libros en objetos extraños y preciosos que los coleccionistas venden y compran por Internet a precios elevados. Más allá de que todavía quede mucho por reeditar, resulta significativo que Aira prefiera que esos textos sigan siendo una rareza y que tampoco entregue a la imprenta alguna de esas novelas de los años setenta.

No sorprende, entonces, que a pesar de la abundante literatura crítica que esta obra ha provocado, esas dos novelas hayan sido poco leídas. Más todavía: la codificación de la obra hace que esos primeros textos puedan interpretarse a la luz retrospectiva de un enorme trabajo de lectura crítica que ha generalizado sus hipótesis. La misma Contreras incluye Las ovejas y Moreira en su corpus utilizando claves de lectura que la obra posterior le permiten estabilizar. En ese contexto, realiza una lectura elocuente de Moreira, pero Las ovejas es apenas mencionada algunas veces. Posteriormente, los diversos trabajos críticos han abordado poco esta novelita, optando por integrarla en corpus mayores (Kohan 1998) o bien considerándola en su relación con problemáticas contemporáneas candentes, como la animalidad (Koller 1990: 127-130).

En este trabajo, propondremos una lectura de Las ovejas que, aunque no desdeña las claves que proporciona la obra completa, intenta al mismo tiempo desprenderse de ellas. Se trata de restituirle a esta novela una extrañeza que la codificación de la obra le ha quitado o, por lo menos, disimulado. Tal extrañeza incluye también a Moreira y especula sobre una posibilidad acaso incomprobable: un Aira setentista, cercano a la vanguardia de Literal, cuya obra inicial, sustraída en su mayor parte a la publicación, revelaría aspectos insospechados de su ars narrativa. Esta lectura la hace posible la misma Contreras: el Moreira de Aira, mito de origen de su noción de "literatura mala", es un Moreira setentista, vanguardista y combativo, en el que los saberes de la época (marxismo, psicoanálisis, teoría literaria) sufren una violencia estética que se tematiza en violencia política (Contreras 2002: 125). ¿Qué nos dice por su parte Las ovejas, escrito dos años antes, acerca del origen, no solo de una noción, la de "literatura mala", sino de la obra misma? ¿No es esta extrañeza del Aira juvenil, desdibujado por la edición del conjunto de su obra y por la codificación posterior, lo que borronea ese origen, posibilitando las genealogías? Una puede ser la de Contreras, la de la literatura mala en Moreira y la del relato de la supervivencia en ambas: supervivencia de la especie en Las ovejas y supervivencia del héroe en Moreira (2002: 19). Pero pueden ensayarse otras genealogías, que se pretendan más ajenas a la ayuda que presta la mirada retrospectiva sobre el conjunto. El darwinismo, por ejemplo, categoría acuñada a partir de lo que Contreras denomina "ciclo pampeano-gauchesco" (2002: 118), no sería la única clave para un pensamiento airiano sobre la vida, las transformaciones, las relaciones entre el individuo y la especie y, finalmente, el límite entre lo humano y lo no humano. Este "vitalismo", palabra con la que se ha relacionado a las vanguardias históricas, permitiría replantear el modo en el que el mismo Aira define su procedimiento de fuga hacia adelante y su poética del olvido. 


\section{LOS ORÍGENES DE LA OBRA: LAS OVEJAS Y MOREIRA}

Aira se refiere a Las ovejas por lo menos en dos oportunidades. La primera, en la entrevista publicada en el ensayo Nouvelles impressions du Petit Maroc. Vale la pena reponer el contexto. Se trata de un texto escrito en la Maison des Écrivains Étrangers et des Traducteurs de Saint-Nazaire, para la colección del mismo nombre. El libro consta del ensayo en español y en francés, seguido de una entrevista en francés. En esta, Aira se refiere a la publicación conjunta de El vestido rosa y Las ovejas. La cuestión gira en torno al problema del género, ya que Aira subtitula "cuento" a El vestido rosa y "novela" a Las ovejas, lo cual es infrecuente en su obra (un ejemplo lo constituye El juego de los mundos [2000a], denominada "novela de ciencia ficción", pero no abundan en sus libros estas especificaciones). Los architextos establecen una presunta inversión o ironía ya que el cuento es más extenso que la novela. Aira introduce sus propias definiciones de cuento y de novela, que también pueden leerse en su ensayo Copi: "la novela es lo que pasa, el cuento lo que pasó" (1991a: 32). Al cuento le es intrínseco el pasado, mientras que la novela es experiencia del presente. ${ }^{1}$ Volveremos sobre esta enigmática definición de novela. Por ahora, nos importa la distinción para comprender por qué la extensión no tiene nada que ver con la denominación. Dice Aira respondiendo al entrevistador:

L'histoire de la robe rose était un exercice pour traquer la réalité de quelque chose qui s'était passé. C'est ainsi que j'ai trouvé le moyen, qui m'avait échappé toute ma vie, d'écrire une nouvelle [La historia del vestido rosa fue un ejercicio para asediar una realidad de algo que ya había pasado. Así encontré el modo de escribir un cuento, algo que se me había negado toda la vida]. (Aira 1991b: 72 , traducción nuestra)

Entonces el entrevistador subraya la presunta paradoja de la extensión de los dos relatos, a lo que Aira responde: "Parce qu'avec 'Les brebis', il s'agit d'un vrai roman qui raconte ce qui se passe, maintenant: la généalogie de Borges en moi, sous la forme d'un exemple" ["Porque Las ovejas se trata de una verdadera novela que cuenta eso que pasa, ahora: la genealogía de Borges en mí, bajo la forma de un ejemplo"] (1991b: 72).

La segunda vez es en otra entrevista, realizada por Guillermo Saavedra en 1993. El entrevistador Ilama "mito de origen de su propia condición de escritor" (134) a la siguiente anécdota del autor:

Un día estaba dando un examen de literatura argentina en la facultad. Hablaba de Borges. Como estoy haciendo ahora, empecé por otro lado. El profesor me interrumpió diciendo que así no se podía exponer la obra de Borges. Me produjo tal indignación que me quisieran decir cómo hablar de Borges que salí del examen y, al día siguiente, me puse a escribir Las ovejas, una novelita donde los animales, a causa de la sed, descubren el idealismo. Tenía 20 años y en ese

\footnotetext{
${ }^{1}$ Contreras piensa la relación entre las dos nociones de este modo: "He aquí también la clave de la forma en que la literatura de Aira conecta la novela con el cuento. En el relato, dice Aira, conviven el pasado del cuento -lo que pasó-y el presente de la novela en que se lo cuenta" (2002: 199).
} 
texto escribí mi versión de Borges, para que nadie volviera a decirme qué es la literatura. (Aira 1993: 134)

En un trabajo muy posterior a su libro, Contreras aborda la relación de Aira con Borges. Aunque elocuente e iluminador, el artículo apenas se refiere a Las ovejas como una "estilización borgiana" (2013: 194), reforzando la conjetura de su libro: al ser el Moreira de Aira una traducción de Juan Moreira de Eduardo Gutiérrez en el estilo de Hormiga Negra, siguiendo la indicación del ensayo "Eduardo Gutiérrez, escritor realista", y apelando a un concepto heterogéneo de traducción, las dos primeras novelas de Aira permiten afirmar que en el origen de la obra está Borges (Contreras 2002: 125-126). No obstante, no se ahonda en esta "versión" que resulta, por lo menos, curiosa y que incluso se presenta bajo la forma del típico chiste airiano: ovejas que descubren el idealismo a causa de la sed. ¿Qué clase de lectura de Borges es esta? En efecto, la misma perplejidad puede plantearse con Moreira: si bien es convincente considerarla un ejercicio borgiano de traducción, ¿no parece más una novela de la constelación Literal? ¿No alude incluso su violencia sexual y su desmesura, de un modo que no se repetirá jamás después, a El fiord de Osvaldo Lamborghini, que Aira había leído poco tiempo atrás?²

Las ovejas y Moreira comparten algunos elementos. Los dos relatos visitan el tópico de la tradición argentina de la pampa y el imaginario gauchesco que convoca. Este imaginario se reactiva conectando la pampa del siglo XIX con esa especie de autobiografía que constituye el conjunto de novelas: pues el paraje tiene un nombre, El Pensamiento, toponimia que designa el espacio propio de la infancia del escritor. Las dos novelas empiezan (en la primera oración) por situar la acción en El Pensamiento, versión airiana de la pampa argentina, zona cercana a la ciudad de nacimiento del escritor, como consta al comienzo del segundo capítulo de Moreira: "Han macadamizado no hace mucho el camino que une la localidad de Coronel Pringles con El Pensamiento" (1975: 15). Este elemento conecta, por un lado, los orígenes de la obra en relación con la tradición literaria nacional (lo que, dicho sea de paso, es un gesto borgiano: la genealogía de la obra coincide con la de la autobiografía, lo que Piglia llama "los dos linajes" [1993: 102-14]) y, a la vez, con la propia obra futura, a través del ciclo pampeanogauchesco.

El otro elemento que comparten es un procedimiento que Aira practicará solo en estas dos novelas (por lo menos hasta lo que sabemos): el plagio. La noción, por supuesto, conecta con la poética borgiana: más allá de la versión de Borges de Las ovejas y de la "traducción" de Juan Moreira siguiendo un ensayo del mismo autor, el procedimiento del plagio evoca la poética borgiana y permite inscribir estos textos también en esa tradición: la de la variación, la tergiversación, la estilización. Moreira, como lo señala Contreras, cita textualmente,

\footnotetext{
${ }^{2}$ Cuando se publicó El santo, Aira declaró en una entrevista que quiso escribir algo erótico, porque había escuchado a alguien decir que en sus novelas nunca había sexo (2015). La afirmación es exacta si se exceptúan Un sueño realizado y Yo era una mujer casada, además de Moreira; pero esta no solo posee escenas sexuales, sino que exhibe un lenguaje soez y pornográfico, ausente de las otras.
} 
sin comillas, dos fragmentos de la novela de Gutiérrez (2002: 125-126). Por su parte, las últimas tres páginas de Las ovejas citan literalmente algunos párrafos del ensayo "Nueva refutación del tiempo", introduciendo unas pocas variaciones para adaptarlo al contexto: los nombres de los filósofos se reemplazan por los de las ovejas, así como otras sustituciones ("Espíritu" por "Virgen Eterna", "hombres" por "ovejas", "Dios" por "Virgen", etc.). Subrayemos, de paso, que los párrafos plagiados del ensayo son, a su vez, una serie de citas de filósofos, que Borges reproduce con comillas, pero en las cuales interviene traduciendo, comentando, parafraseando. Es decir que se trata de la cita sin comillas de una serie de citas.

También, finalmente, ambas novelas están pobladas de vida animal. Moreira abunda en animales que parlamentan con los protagonistas como si se tratara de criaturas de una fábula, aunque el deliberado surrealismo de las escenas complica esta adscripción genérica, así como cualquier realismo o mera verosimilitud. Y aunque Las ovejas tampoco parezca una fábula, no habría que descartarlo de modo apresurado: Aira ha leído "Josefina o el pueblo de los ratones" de Franz Kafka como una fábula del artista del siglo xx (Aira 2021: 208-217). Como en el cuento de Kafka, en esta fábula que sería Las ovejas no está tan claro lo que se quiere demostrar. Podemos conjeturar que se trata de una mezcla de fábula y de exemplum filosófico. ${ }^{3}$

Desde este punto de vista, Las ovejas y Moreira pueden pensarse como el examen, vía Borges, de las dos doctrinas filosóficas a las que puede reducirse la historia de la filosofía: el idealismo y el materialismo. En efecto, no solamente Moreira alude al materialismo y al marxismo, convocando una discusión común en su época, sino que su materialidad abyecta, corporal y sexual, lamborghiniana, caracteriza su versión del gaucho malo de Gutiérrez. Si conjeturamos que la poética de Moreira tuvo poca descendencia en la obra airiana, más allá de poder adscribirse a un tipo de imaginación surrealista, podríamos considerar esta doble genealogía como una toma de partido (relativa, irónica, táctica) tanto por el idealismo filosófico como por la poética borgiana. Por ejemplo, en su ensayo Copi: "En esta dirección nos alejamos de la consideración 'material' del texto o la obra de arte en general. Ese tipo de crítica me parece errónea y nefasta. La literatura es una actividad fantasmática, sin materialidad alguna" (1991a: 60). Esta oposición, y su correlativa posición polémica, refuerza el parentesco de Moreira con la vanguardia de Literal: una concepción materialista (la importancia del significante) y textualista de la práctica literaria (el acento puesto en el concepto de "escritura" por sobre el de "literatura") (Peller 2016: 174-180). Como muchas novelas de los escritores relacionados con esa vanguardia, Moreira abunda en alusiones a Freud, a Lacan, a Joyce, a Shakespeare, a Marx, a Saussure, al telquelismo y al textualismo de la época, aunque montadas de una manera que su exhibición está cargada de un cinismo que también evoca los textos de Lamborghini.

\footnotetext{
3 "Lo que llama la atención en esta primera novela es la voluntad de construir una ficción absolutamente personal y alejada de cualquier aplicación mimético realista, en todo caso más cercana a la alegoría, al planteo surrealista y al exemplum de corte filosófico" (García 2006: 35).
} 
Desde luego, la posición cínica del texto es también el efecto de la yuxtaposición de alusiones hiper-literarias en el pastiche humorístico y soez de la prosa, procedimiento asimismo lamborghiniano. El choque de heterogéneos produce el mismo efecto cínico que el final de Las ovejas, cuando el nombre de una, "Moussy", reemplaza a "Berkeley" y en la última línea "las ovejas" reemplazan a "David Hume" (1984: 151-152). No obstante, mientras el pastiche carnavalesco de Moreira exhibe una factura cínica desde el comienzo hasta el final, Las ovejas, en cambio, solamente en el final parece someterlo todo al sarcasmo, por lo que no puede decirse tan fácilmente que el texto establezca una posición respecto del idealismo. Volvemos entonces a plantear la pregunta: ¿cuál es la versión que la novela hace de Borges? ¿Se trata, acaso, de una extraña fábula que cuenta esa misteriosa genealogía? ${ }^{4}$

\section{LA ANIMALIDAD EN BORGES}

Retomemos el imaginario en el que se sitúa la historia. La crítica ha dicho que la pampa de Aira es una desrealización del Desierto que forjaron los textos fundantes del XIX (Gramuglio 1982). Mientras que Echeverría, Sarmiento y Mansilla desertificaron un territorio que en realidad estaba poblado, justificando en última instancia el genocidio de la campaña de Roca, ${ }_{1}^{5}$ las novelas de Aira no solo restituyen a la pampa del XIX una población diversa, sino que lo hacen en una proliferación barroca, exuberante: la pampa de Ema, la cautiva (1982) y de La liebre (1991c) (las novelas con las que Contreras establece el ciclo) desborda de vivientes humanos y no humanos, es una pampa llena, en donde el vacío del Desierto de los clásicos no tiene, precisamente, lugar. Ahora bien, antes de esta operación de llenado, Las ovejas operan otro vaciamiento: el de lo humano. ${ }^{6}$ Pero no solo de lo humano: la pregunta por el estatuto de lo real, que desembocará en el descubrimiento final de la doctrina idealista, nace de una incertidumbre respecto de lo que las ovejas perciben a su alrededor. La pampa de El Pensamiento, en esta primera novela, lejos de ser esa inversión que llena lo vacío, es, por el contrario, una hipérbole de la operación de los textos fundantes: el motivo de la sequía es la causa de que la vida

\footnotetext{
4 Para Margarita Remónd-Raillard, Las ovejas puede leerse en la mezcla entre ensayo y ficción, de prosapia borgiana, que el mismo Aira continúa en su propia obra de un modo singular (2003: 120). La conjetura es sugerente, pero no es nuestra lectura: para nosotros, es muy clara la distinción, en la obra de Aira, entre ensayo y relato, aunque algunos textos mucho más recientes, como Continuación de ideas diversas (2014), propongan una fusión en este sentido. En nuestra lectura, Las ovejas es una novela, tanto más cuanto funda el espacio de la ficción airiana. Los pensamientos filosóficos o seudo filosóficos, así como toda clase de ideas inventivas, como componentes de la ficción, constituyen otro problema, lo que incluye Las ovejas, pero que no implica necesariamente la mezcla con el ensayo (Contreras 1993, Podlubne 1996).

${ }^{5}$ La bibliografía sobre el tema es muy extensa. Remitimos al excelente libro de Fermín Rodríguez (2010), que consta de un estado de la cuestión muy completo.

${ }^{6}$ El vestido rosa, fechada en 1982 y publicada junto con Las ovejas en 1984, realiza otra operación de vaciado, en un juego de simetrías y de inversiones con los textos fundantes. Cuando la campaña genocida de Roca llega al Desierto, no encuentran a los indios. La operación poético-política de desertificación, de Sarmiento a Mansilla, tiene la consecuencia paradójica, y mágica, de escamotear la materialidad corporal de los indios que, cuando van a ser aniquilados en el Desierto, no pueden ser hallados.
} 
haya abandonado la llanura, empezando por los humanos que se van a la ciudad dando por perdido un año de cosecha y dejando el ganado librado a su suerte. Esa pampa, cuya percepción despierta en la tenue conciencia de los animales perturbados por la sed, es también un espacio abstracto, desprovisto de materia, pura imagen de ensoñación y de especulación: un espacio de pensamiento, "metafísico".7

Esta hipérbole del vaciamiento de los textos fundantes es, por otro lado, el correlato de una serie de sustituciones o inversiones. La primera, el sujeto humano es reemplazado por un animal (sin que el relato se convierta nunca en una fábula): un animal, además, de una especie particular. Tenemos entonces una pampa en la que la aventura será no-humana. Además, si el imaginario gauchesco, desde la poesía gauchesca hasta Don Segundo Sombra de Ricardo Güiraldes, pasando por Juan Moreira, es predominantemente masculino, los animales de esta aventura son hembras, que además desconocen la diferencia sexual (Moreira, por el contrario, es una novela pletórica de sexualidad). Si el imaginario gauchesco, por su parte, evoca una vida esencialmente diurna, una jornada laboral o aventurera dominada por el sol, las ovejas, en contraste, se han vuelto nocturnas, lo que contribuye a esa atmósfera abstracta y onírica. Por último, si la gesta gauchesca es casi exclusivamente individual, definida por el nombre propio (Martín Fierro, Juan Moreira, Don Segundo Sombra), de modo que el mismo Borges pudo reducir el motivo de la guerra a su núcleo argumental básico (el duelo entre dos individuos, desde luego, humanos y masculinos), la aventura de la novela de Aira es en cambio colectiva: la lucha por la supervivencia de la especie.

Pero ¿por qué ovejas? La elección de la especie no parece casual. Contreras afirma que la naturaleza de Ema, la cautiva no es la del territorio de la literatura gauchesca, sino la que observan los naturalistas viajeros que vienen del extranjero (2002: 50). Para precisar ese territorio de la gauchesca, contra el que se recorta la naturaleza exuberante de Ema, la cautiva, Contreras remite a Muerte y transfiguración del Martín Fierro de Ezequiel Martínez Estrada y a El río sin orillas de Juan José Saer (2002: 102). Ambos coinciden en señalar que los tres animales característicos de este territorio son el caballo, el perro y la vaca. El caballo, dice Saer, traído por los españoles, es muy pronto adoptado por los indios, llegando a ser el símbolo característico del gaucho, al que sin embargo precede en siglos. Los perros, en bandas cimarronas, conviven igualmente con los indios, como queda claro en Una excursión a los indios Ranqueles de Lucio V. Mansilla, cuyo narrador además tiene su propio can. El ganado vacuno, finalmente, es la base de la economía rural del siglo XIX, hasta la llegada de los inmigrantes que fundan las primeras colonias y empieza a crecer en importancia la explotación agrícola. ${ }^{8}$

\footnotetext{
7 "Prolongando una comparación esbozada y remontando la historia literaria, recordemos que, en la primera 'novelita' de César Aira, Las ovejas (1970), la entrada en la escritura pasa por una insolente puesta en escena borgeana y pampeana; en ella, las ovejas, que llevan adorables nombres ingleses -Cathy, Pety, Moussy, Poppy- postulan, en sus intercambios, un idealismo a la Berkeley, perdidas como están en la previsible inmensidad metafísica de la llanura literaria" (Premat 2020: 10).

8 "Y esas tres especies domésticas, compañía ancestral del hombre en sus reductos civilizados,
} 
En el contexto de este imaginario animal, las ovejas parecen una operación de desplazamiento metonímico. Vuelven extraño ese territorio vaciado por la sequía conservando la vida de la llanura, pero desplazándolo de sus animales característicos. Curiosamente, el comienzo de Juan Moreira las menciona: "Hasta la edad de treinta años fue un hombre trabajador y generalmente apreciado en el partido de Matanzas, donde habitó hasta aquella edad, cuidando unas ovejas y unos animales vacunos, que constituían su pequeña fortuna" (Gutiérrez 2012: 12). ¿Podrían ser estas ovejas las de Moreira? Finalmente, el extracto que Strafacce cita de Zilio, novela inédita de Aira escrita en los setenta, narra el combate entre su protagonista y una feroz oveja, que resiste las heridas de bala de modo inverosímil hasta que por fin muere cuando un disparo atraviesa sus genitales (2008: 460-461). Retomaremos esta insistencia en la "vaginalidad ovina" (Aira 1984: 100).

Durante la seca, las ovejas sobreviven por su resistencia a la sed y al hambre: "el ganado vacuno había ido despareciendo poco a poco y el campo se poblaba de sobrevivientes, casi siempre cimarrones" (1984: 96). La virginidad es un elemento que contribuye a esa resistencia, como si la actividad sexual fuera parte del desgaste de una especie: "Lograron sobrevivir en este estado los animales más ascetas, los más ricos, y los de sexo femenino" (1984: 110). Si el caballo, el perro y la vaca son, para el imaginario gauchesco, animales cercanos al hombre pero que, como se vio, precedieron a su habitante característico, el gaucho, la oveja, en cambio, si bien objeto de explotación económica, conserva su extrañeza, escapando a esa tipicidad. Podría tal vez afirmarse que, antes de repoblar la pampa, la narrativa de Aira restituye a la animalidad su precedencia de lo humano. Es decir, libera lo animal de su captura simbólica, devolviéndolo a ese tiempo arcaico en el que el hijo del país todavía no se había convertido en el habitante típico. Esta operación encuentra su traducción en la poética de vanguardia, que en los años setenta asume la forma de la violencia formal: una poética altomodernista (Joyce, Borges) pero "cimarrona", salvaje, lamborghiniana. Una inversión de ese criollismo de vanguardia del Borges de los años treinta (Sarlo 2007: 160-166) o una versión de esa "vanguardia bizarra" (Montaldo 1998: 12): una vanguardia cimarrona.

Para Contreras, la pampa de Ema, la cautiva y de La liebre es la del extranjero naturalista, que la puede observar en su detallismo y diversidad científica, motivo por el cual puede hablarse de un "darwinismo airiano" (2002: 17). Los motivos de la supervivencia de la especie, de la mutación y de la variación genética, corroboran esta denominación. Ahora bien, Las ovejas presenta una pampa diferente, más abstracta, más parecida a la que imagina Rugendas en Un episodio en la vida del pintor viajero (2000b) y que no llega a conocer. Se trata de una pampa como espacio de pensamiento, en la que el problema del idealismo, vía Borges, se plantea en términos de una mente no humana. Aunque el final de la novela pueda parecer una mera broma, no habría que subestimar el problema

señorearon en estado salvaje, durante dos siglos, la llanura. Los lomos de sus manadas numerosas hicieron ondular, sin encontrar ningún obstáculo en sus desplazamientos, el horizonte de la pampa" (Saer 2002: 77). 
del estatuto de la realidad en relación con el proceso de percepción, cuando el que percibe no es humano. La preferencia borgiana por los filósofos y pensadores ingleses resulta significativa en este punto. Si la pampa de Ema, la cautiva y La liebre convoca persuasivamente el nombre de Darwin, la pampa abstracta de Las ovejas, en cambio, parecería poder considerarse mejor a la luz de la obra de un escritor que parece no estar citado, pero que también es una clave borgiana: Samuel Butler.

En efecto, Jaime Rest afirma que en la antropología borgiana confluyen tres principios: evolucionismo, voluntarismo e inconsciente (2003: 73). El voluntarismo se refiere a la concepción de Arthur Schopenhauer, que en el desenlace encarna la oveja Cathy. El inconsciente evoca no a Freud, que Borges desdeña, sino a la teoría de los arquetipos de Karl Jung. En cuanto al evolucionismo, Borges reivindica a Butler por sobre el pensamiento de Darwin (Rest 2003: 73-74). Estos tres principios operan una crítica del humanismo: la voluntad schopenhaueriana es una fuerza que excede todo querer individual y abarca no solo la vida del planeta, sino también la materia, la energía y el cosmos; los arquetipos de Jung implican un patrón inconsciente de comportamiento que opera a nivel colectivo, es decir, que excede al sujeto individual, pero también a cualquier sujeto colectivo; el evolucionismo butleriano, finalmente, implica no solo la preeminencia de la especie por sobre el individuo, sino también una singular concepción de la vida y, como poco después hará Jakob Von Uexküll, la negación tanto de la superioridad de ciertos animales sobre otros como del concepto de "selección natural" de Darwin. Las ovejas podría ser, entonces, una lectura de esta antropología borgiana (la novela de Aira es anterior al libro de Rest, al que parece anticipar en este problema). Esta lectura, además, tiene consecuencias decisivas para la definición de la poética airiana. Si en el origen de esta obra está Borges, la animalidad trama una versión que desplaza esta antropología y permite, tal vez, volver a pensar ese "ciclo darwiniano".

Borges no se interesa específicamente por los animales. ${ }^{9}$ Una de las pocas ideas sobre ellos se relaciona con su inconsciencia de la muerte. Entre las escasas menciones encontramos la de "El sur", incluido en Ficciones:

Ahí estaba el gato, dormido. Pidió una taza de café, la endulzó lentamente, la probó (ese placer le había sido vedado en la clínica) y pensó, mientras acariciaba el negro pelaje, que aquel contacto era ilusorio y que estaban como separados por un cristal, porque el hombre vive en el tiempo, en la sucesión, y el mágico animal, en la actualidad, en la eternidad del instante. (Borges 2007a: 634)

\footnotetext{
${ }^{9}$ Esta afirmación puede ser matizada. Para ser más precisos, habría que decir que no se interesa en la animalidad como problema específico, tal como lo vienen haciendo los Animal Studies. Para el cometido de este artículo, atenderemos a las menciones aparentemente casuales de Borges, en las que los animales parecen meros ejemplos o casos. En ese sentido, El libro de los seres imaginarios, escrito en co-autoría con Margarita Guerrero, plantea problemas por completo diferentes, ajenos a nuestra zona de interés, pero seguramente productivos para considerar de otro modo la cuestión animal (Oliveira 2019).
} 
Con la sed, lo que las ovejas presienten es precisamente la intuición que se le niega al animal:

Los animales, en sus eco-sistemas, viven entregados al afán de ocultar cada posible rastro de la muerte, se disimulan, o mimetizan, en una minuciosa eternidad. Ahora hasta esa amable costumbre se había disipado, y todos veían con sus propios ojos el carnaval despiadado que descubría la sed. (Aira 1984: 96)

No solo la escena parece evocar la de Dahlmann con el gato, sino que el adjetivo "minuciosa" aplicado a "eternidad" parece también borgiano. Las ovejas de El Pensamiento despiertan a la conciencia de la muerte y por eso descubren la filosofía. En consecuencia, sugieren que cualquier viviente descubriría el pensamiento a causa de esa misma conciencia. Pero en esa idea borgiana sobre la animalidad hay más. "Nueva refutación del tiempo", el ensayo con el que termina la novela, se propone llevar más lejos las tesis idealistas sobre la negación del sujeto, del objeto, de la identidad personal y del espacio, y negar también el tiempo. El recorte de Aira no llega a esta refutación. No obstante, podemos conjeturar que el relato la sugiere: la experiencia del instante, la existencia efímera del instante como autónomo ("cada momento que vivimos existe -dice Borges-, no su imaginario conjunto" [2008: 170]), es la experiencia que el "El sur" atribuye a los animales. Aira le agrega al derrotero borgeano su propio ejemplo, en un golpe que desarma la argumentación, o la vuelve inútil (aunque el mismo Borges, en el ensayo, yuxtapone experiencias a modo de ejemplos o figuraciones): la refutación del tiempo, que en la argumentación del pensar humano está "después" de las otras refutaciones (el sujeto, el objeto, la identidad personal, el espacio), y que lo arrojarían a una experiencia animal, también está "antes". En un círculo que anula justamente la temporalidad, esa experiencia, puramente especulativa para el pensamiento humano, se postula como algo in-humano, animal. Las ovejas de Aira salen de ella para encontrar el pensamiento. Además, si el idealismo de Berkeley, pero más radicalmente el de Hume, niega la necesidad de una sustancia espiritual (o sujeto) que fundamente las percepciones, el problema de la humanidad o inhumanidad de ese sujeto ni quiera parece relevante.

En Vida y hábito, Butler conjetura que existe una memoria de la especie que permite explicar todas las acciones del ser vivo, incluso las aparentemente instintivas, mediante el hábito. Las acciones que se llaman instintivas son, en realidad, hábitos muy antiguos que conserva la especie pero que el individuo ha olvidado haber adquirido. Butler niega una diferencia cualitativa entre el viviente humano y el viviente no humano. Su particular mentalismo, que se inscribe en el pensamiento inglés desde Berkeley hasta Francis Bradley, lo lleva a otorgar a los vivientes no humanos esos atributos que la filosofía moderna consideró como exclusivos del hombre: el deseo, la comunicación, la volición y la inteligencia (Butler 2013: 189). La vida no es otra cosa que el hábito adquirido por la repetición de una acción. Solo la novedad introduce una inestabilidad en el sistema que obliga al viviente a aprender: en el caso de las ovejas, esta novedad es la sed. La circunstancia de que la sequía continúe hace que no solo las ovejas sino todos los animales supervivientes se vean obligados a agotar esta memoria de 
la especie o crear nuevos hábitos para adaptarse, como la hormiga que muere a manos de Moussy: "Aunque estaba segura de su muerte, impuso una resistencia afanosa. Empleó todos los trucos de guerra que conocía, todos los que había aprendido en el ADN" (1984: 131).

Dijimos más arriba que la pampa abstracta de Aira restituye los animales a su estadio pre-humano y pre-simbólico. En efecto, Las ovejas narra la lucha de la especie por la supervivencia, pero también el despertar de una percepción del mundo que antecede a la palabra y que podemos llamar imaginaria o pre-simbólica. Solo cuando, al final, descubren el idealismo, las ovejas hablan ("Como ignoraban la conversación, permanecían en silencio" [1984: 102]): la palabra coincide con el estadio filosófico. Sin embargo, la aventura es el despertar de su mente ovina a la percepción fantasmática de la pampa. En el comienzo de la historia, las ovejas pasan de experimentar sus propios cuerpos a traducir esas sensaciones a emociones, como el miedo. El relato insiste en que el sueño de los animales es "sin imágenes" y que su despertar no implica al principio la visión, sino experiencias como la locomoción, la sensación de estar de pie, la inmovilidad y la movilidad. Cuando van en busca de alimento y de agua, casi no perciben el mundo físico, distraídas y olvidadizas. Si prestan atención, es por alguna situación insólita que las arranca del hábito, como en el episodio en el que la gaviota da muerte a la hormiga: "Las ovejas de aquel círculo habían visto todo. No sabían si admirar la audacia y movimientos frenéticos de la gaviota, o compadecerse de la muerte injusta de la hormiga. En la duda, se produjo el paso a un suave olvido" (1984: 104). Este olvido de lo que se percibe tiene resonancias nietzscheanas y podría también haber contribuido a la concepción borgiana del eterno instante en el que vive el animal. Las ovejas pasan de la inmovilidad, la inercia, el adormecimiento, a la movilidad que causa la necesidad: "Las ovejas sentían catalepsia. No movían un pelo. Pero adentro, el corazón se agigantaba; un tableteo constante, que era un canto, no un discurso. Las mentes, en blanco" (1984: 104). Este blanco de la mente se va a ir poblando de imágenes a medida que la necesidad las vuelva más osadas y desesperadas, y la vida nocturna, que ya es una adaptación, se vuelva cada noche menos rutinaria (menos habitual) a causa de esa sed que no pueden aliviar. El hábito recién adquirido, la mutación a la vida nocturna, se experimenta como un recuerdo difícil de asir, que todavía no es memoria, pero que ya posee la intensidad como para no ser olvidado:

La vieja y sabia Moussy miró el horizonte. Todo lo que se veía era blanco, pero sentía algo más. Sus percepciones le indicaban algo más. Se sentía a punto de capturar las Gracias del mundo, con una sola idea. Al fin lo recordó: pronto sería de noche y gozarían de cierta frescura. (Aira 1984: 105)

La atención microscópica del narrador, que vuelve naturalista esta mirada, examina el paso de la percepción a la sensación, de la sensación a la emoción, y de la emoción al recuerdo que permitirá la repetición y el establecimiento de un hábito. La suma de peripecias extrañas que ocasiona la lucha nocturna por la supervivencia favorecerá entonces la mutación: "Pero la aventura no había terminado. Estaba escrito que aquella noche debía grabarse con letras de fuego en la memoria de 
las ovejas" (1984: 121). La sed continua, la imposibilidad de adaptarse al medio inhóspito, el presentimiento de la muerte, despierta la conciencia del mundo y la pregunta por el estatuto de las cosas: "lo real no les parecía real, no sabían por qué" (1984: 105).

Cuando la oveja Kitty se encuentra en el campo vacío con un pájaro que la hiere, lo confunde con una "oveja evolucionada" (1984: 113). La especie, entonces, adquiere un rudimento de pensamiento por analogía: las otras especies, la pampa vacía y el cielo estrellado les plantean enigmas a los que ellas responden con lo que conocen, su propia especie. La mímesis, en consecuencia, precede un pensamiento mágico: "Y al levantar los ojos, vieron un inmenso pájaro blanco... [...] Un escalofrío recorrió la majada. Aquella visión podía traer mala suerte" (1984: 114). Esta visión anticipa las alucinaciones colectivas que provocarán las grandes migraciones con las que finaliza la novela.

Ahora bien, la mutación, excediendo el límite darwiniano, afecta todas las formas, como si la fuerza vital fuera parte de otra más grande, que la abarcara, y que pareciera confundirse con esa "voluntad" de la que habla Borges siguiendo a Schopenhauer:

Los días y las noches veían raros espectáculos, pues todas las formas habían mutado. La adaptación, más allá de lo real, se volvía teatral, y la supervivencia funcionaba de noche, por ser insoportable el calor diurno. La fauna había comenzado a interiorizarse de la intrincada astronomía, especialmente los pequeños animales, incluso los que vivían en las entrañas de la tierra. (Aira 1984: 126)

La atención que la majada empieza a prestar va de la mirada microscópica a ese suelo casi desertificado, de aspecto lunar, al cielo estrellado, en el que las formas que empiezan a notar parecen llevarlas hacia un estadio mitológico o pre-teológico: "Nada de lo que poblaba el cielo les resultaba explicable, ni mucho menos. Sobre todo una constelación, la más alejada hacia el noroeste, en ella creían ver una figura cuyo significado se les escapaba: el Carnero. Jamás habían visto un ser masculino" (1984: 117). Como facultad, la imaginación, según Hume, permite la libre combinación de figuras para construir algo que sin embargo no se ha percibido nunca (Chávez Tortolero 2016: 55): ${ }^{10}$ es lo que las ovejas comienzan a practicar, una vez que la lucha por la supervivencia las despierta a la observación de las cosas. La majada, que en el primer capítulo no sabía por qué "lo real no les parecía real", pasa de la meditación al movimiento porque los espejismos del desierto le plantean la pregunta por ese real que es producto de la alucinación, es decir, de la proyección imaginaria de la necesidad convertida en deseo: todas las imágenes, en su diversidad, son diferentes formas del agua que no pueden beber. La constatación de la irrealidad de las imágenes las coloca ante el problema que,

\footnotetext{
10 A propósito de la facultad de la imaginación en Hume: "Puesto que podemos hablar de cosas que nunca hemos visto, y en esa medida considerar la existencia de objetos que pueden estar presentes en la mente y formar parte de la experiencia sin la intervención de los sentidos" (Chávez Tortolero 2016: 55).
} 
en su lectura de Berkeley, obsede a Borges: la existencia de las cosas fuera de un espíritu (Berkeley habla de espíritu y no de conciencia) que las perciba. Rest afirma que Borges suscribe el idealismo de Berkeley. ${ }^{11}$ Pero hay otros críticos, más sensibles a la ambigüedad borgiana, que consideran, en contraste, una posición oscilante:

A la luz de este pensamiento sin duda excesivo, las ficciones de Borges oscilan entre una sumisión estricta a la norma del esse est percipi y la postulación de su inversa. Por una parte, todo reclama la mirada del espíritu para ser verdaderamente; por otra, todo ser verdadero se afirma en una suerte de objetividad sin testigos. (González 1993: 31)

Los espejismos que impulsan la migración de la majada, y que desembocan en el descubrimiento del idealismo, plantean este dilema: para los animales, las cosas, en efecto, solo son en cuanto se perciben y solo se perciben en cuanto adquieren un sentido práctico. El hecho de que la sed continúe lleva a las ovejas más allá de ese sentido práctico, a la contemplación del cielo y a la exploración de la llanura. La des-humanización de la pampa de El Pensamiento contribuye asimismo a esa imaginación borgiana de un universo cuya perfección parece la consecuencia de un existir sin mácula de espíritu alguno que amenace, con su percepción relativa, su perfección o pureza: si suscribimos, claro está, que ese espíritu deba ser necesariamente humano. Darío González da los ejemplos de Berkeley caros a Borges: una arboleda en un prado, libros en una biblioteca sin nadie que los lea (González 1993: 37). Ese nadie, ¿puede no ser humano? La melancolía de las cosas que se pierden porque no hay una conciencia que las perciba o memoria que las retenga es uno de los extremos borgianos: el otro es la existencia como condición que prescinde de la percepción que la sostenga y la haga "ser". "Tlön, Uqbar, Orbis Tertius", como ha sido señalado, postula un planeta en el que los habitantes son idealistas, en el sentido de Berkeley (Martin 2002: 10-11): las cosas no persisten fuera de la conciencia de los sujetos. En Tlön, es el materialismo lo que resulta incomprensible. Por el contrario, no solo las cosas dependen de los sujetos que las perciben, sino que se imponen a la realidad como objetos puros, creados por la mente. Borges, que siempre parece pensar en términos antropomorfos, reintroduce sin embargo un curioso ejemplo, en el que, de nuevo, Las ovejas podrían haber abrevado:

Las cosas se duplican en Tlön; propenden asimismo a borrarse y a perder los detalles cuando las olvida la gente. Es clásico el ejemplo de un umbral que perduró mientras lo visitaba un mendigo y que se perdió de vista a su muerte. A veces unos pájaros, un caballo, han salvado las ruinas de un anfiteatro. (Borges 2008a: 525)

Tal vez por eso Rest hable de antropología: en los vericuetos del razonamiento y de la argumentación, la imaginación borgiana encuentra, casi sin darse cuenta, experiencias que la filosofía busca por vía de la especulación. Si la refutación del

${ }^{11}$ Con matices, otros críticos también lo afirman. Para una pormenorizada lectura del idealismo inglés en Borges, véase Martin (2000 y 2002). 
tiempo encuentra una experiencia persuasiva en el gato que acaricia Dahlmann (escena que, para complicar las cosas, sucede en un sueño del personaje) y el argumento de Berkeley puede ser desestabilizado por el ejemplo de los pájaros y el caballo en el anfiteatro, entonces la percepción de ese "alguien" puede no ser humana. Y, en efecto, en el obispo Berkeley no lo es: es divina. Si nadie contempla, Dios es entonces el que contempla. Es el estadio ya teológico de las ovejas en el final. En la cita de Borges en la que Berkeley dice que las cosas siempre son percibidas por algún espíritu y, si no hay ninguno, es Dios quien las percibe, el texto de Aira dice: "es la Virgen quien las percibe" (1984: 151). Así como el Carnero es una figura percibida que no pueden pensar (porque nunca vieron un ser de la misma especie de género masculino, aunque puedan imaginarlo), la forma de la divinidad adopta la de una Virgen: no el Dios antropomorfo que se esconde detrás de la teología humana, sino la diosa animal que presiente la majada. Este matiz de crítica al falocentrismo del pensamiento occidental explicaría la insistencia en la feminidad ovina: "Eran muy femeninas, y no solo por lo rosado de los genitales, sino por los gestos, que nunca abandonaban la volubilidad de lo real, y sobre todo por la relación que mantenían entre ellas, tan fina y ligeramente histérica, con el matiz de la vaginalidad ovina" (1984: 100). ${ }^{12}$

\section{UN EVOLUCIONISMO NO DARWINIANO}

Butler, al discutir la noción de instinto y considerar la vida como aprendizaje y hábito, no solo atribuye a los vivientes no humanos aquello que presuntamente hace humano al hombre (volición, inteligencia, comunicación), sino que considera la vida misma como un arte, cuestionando en última instancia la separación entre naturaleza y cultura:

No puedo ver entonces dificultad alguna en el desarrollo de los así llamados ordinariamente "instintos", sean de hormigas o de abejas, o del cucú, o de cualquier otro animal, bajo el supuesto de que fueron en su mayor parte adquiridos inteligentemente con mayor o menor trabajo según el caso, casi de la misma naturaleza en que vemos cualquier arte o ciencia en proceso actual de adquisición entre nosotros, pero que fueron finalmente recordados por el vástago, o les fueron comunicados. (Butler 2013: 191)

Para Contreras, la imaginación genética y mutante de Aira puede relacionarse con el vitalismo de la vanguardia (2002: 17). En efecto, este vitalismo, que podemos llamar butleriano, implica una indistinción entre naturaleza y cultura. Si, para Aira, se trata, en arte, de la acción (no del producto terminado, no de la contemplación artística, sino del proceso, del hacer [Contreras 2002: 16-17]), también para Butler se trata de la vida considerada en su dimensión de praxis. Lo más humano, o lo más sofisticado que ha alcanzado la civilización, el pensamiento, la filosofía, la ciencia y las artes, no son, en definitiva, más que una respuesta "adaptativa" de la especie

\footnotetext{
12 En este sentido, no es casual que, en la edición, la novela sea precedida de El vestido rosa, otra historia con un aura de feminidad.
} 
para poder habitar el universo, una práctica que se ejercita. La contemplación y la meditación también son, en definitiva, acciones: surgen de una necesidad, de una dificultad que plantea el entorno físico.

Ahora bien, considerar este vitalismo en términos de Butler permite conectar la imaginación genética de Aira con la concepción borgiana de la literatura ( $y$, en general, de toda actividad humana, de toda "vida espiritual") $y$, en consecuencia, en el origen de su narrativa, con su propia concepción de la obra de arte. En el centro de esta conexión se encuentra la tensión entre la afirmación de lo individual y la importancia dada a lo impersonal. Esta tensión es la que Aira analiza en el único texto que escribió sobre Borges, "La cifra". Para Aira, la obra de Borges consta de dos momentos: el de la juventud vanguardista, en el que participa junto con su generación de una tentativa colectiva, y el de su reinvención personal, en la que empieza de cero, desdeñando toda empresa colectiva y desertando de su juvenil criollismo de vanguardia y de su martinfierrismo. Esta oscilación es la que también señala González: por un lado, el elogio inglés del sujeto individual, el nombre propio como rúbrica y, por el otro, la idea de un sujeto único, un nadie anónimo, como esos libros de Tlön que no se firman y a los que la lectura junta para inventarle un autor. Dice Aira en "La cifra":

Este agnosticismo cultural debería apoyarse en una valoración del yo autónomo, de la personalidad característica, del personaje actuando como paradigma individual y dictando temas, formas y afectos. Y lo hace realmente, pero en dos niveles heterogéneos, en una dialéctica no resuelta que sigue constituyendo el enigma y el encanto de Borges. Los términos de esta dialéctica estaban planteados en un ensayo de juventud, "La Nadería de la Personalidad", donde no niega al individuo pero sí su "constancia" en el tiempo. El yo es momentáneo y presente, a reconstruir cada vez; el yo como personaje constante sería una suma imposible, "nunca realizada ni realizable". (Aira 1999: 3)

Butler dedica los capítulos V y VI de Vida y hábito a discutir la idea de identidad personal, en términos no solo muy parecidos a los del ensayo de Borges que cita Aira, sino incluso, en sus momentos menos verosímiles, con argumentos parecidos a los de "Funes el memorioso", en donde otra vez nos encontramos con un animal:

No solo le costaba comprender que el símbolo genérico perro abarcara tantos individuos dispares de diversos tamaños y diversas formas; le molestaba que el perro de las tres y catorce (visto de perfil) tuviera el mismo nombre que el perro de las tres y cuarto (visto de frente). (Butler 2007a: 589)

Tomando al pie de la letra a Darwin, afirma Butler, las variaciones entre las especies, si la historia de la vida en el planeta no hubiera estado llena de cataclismos y de extinciones, anularían la radicalidad del "salto evolutivo". Entre una especie y otra, habría muchísimas intermedias, de modo que sería imposible una clasificación, y la vida mostraría su continuidad absoluta, y también su absoluta diversidad, desde el renacuajo al hombre civilizado: 
Actualmente se sostiene, gracias a Mr. Darwin, que las especies se mezclan o se han mezclado entre sí; de modo que cualquier posibilidad de ordenamiento y aparente subdivisión en grupos definidos se debe a la supresión por muerte tanto de individuos como de géneros enteros, que de estar existiendo hoy, hubieran vinculado a todos los seres vivientes por una serie de gradaciones tan sutiles que no podría haberse intentado una clasificación. (Butler 2013: 91)

Esta continuidad absoluta y esta diversidad absoluta como opuestos que se igualan parece ser la clave de la paradoja de la propia obra airiana. En la versión que de la poética de Aira se ha estabilizado, el ready-made de Duchamp resuelve esta tensión entre lo individual y lo impersonal: el arte no es producido por el individuo, sino que "se hace solo", es una singularidad histórica, pero es el artista individual quien "lo encuentra" y "lo firma":
Se trabaja como individuo. Y lo nuevo no se entrega a los esfuerzos del artista individual. Lo nuevo es (y aquí la Historia, la historia de los hijos de Baudelaire, da con la mayor discreción un paso adelante) "lo que debe ser hecho por todos, no por uno". Lo nuevo es impersonal, intersubjetivo, inevitable. Está en el aire, o no está en ninguna parte. (Aira 1995: 29)

Ahora bien, si traducimos esta concepción, esta apropiación que hace Aira de la
oscilación borgiana, a los términos de Butler, de modo de desplazar el supuesto
humanista de Borges, tal vez pueda entenderse de otro modo ese "vitalismo"
de la vanguardia que es precisamente el componente airiano que la poética de
Borges rechazaría. Las ovejas restituye este componente, que tampoco es forzado
extraer de Borges, por cuanto el evolucionismo de Butler, como lo conjetura Rest,
sería una de las claves de su antropología. En esta restitución, el vitalismo airiano,
vanguardista, adquiere su singularidad, que no es darwinista, sino genética en
este sentido de Butler. Si nuestra hipótesis es correcta, podemos incluso discutir,
contra el mismo Aira (y la crítica en general ha tendido a seguirlo en este punto), o al menos contra la posición que declara, su poética del olvido.

Como lo deja claro en su Copi, el olvido es el procedimiento que permite seguir escribiendo, en la fuga hacia adelante del relato, sin preocuparse por lo absurdo o el sinsentido. La memoria, por el contrario, implica la retención de lo que se escribió antes y, también, de lo que pasó en la historia narrada. Le poética del olvido tiene como consecuencia la no corrección, la desprolijidad, la necesidad de "verosimilizar" hacia adelante. Mientras que la poética de la memoria es justamente reescribir, corregir, de modo que la historia contada tenga una armonía, una forma reconocible. Dice en Copi: "La memoria tiende al significado, el olvido a la yuxtaposición" (1991a: 33). Sin embargo, este imperativo de olvidar parece entrar en tensión con otro: el de la "automatización del procedimiento". Dice Aira: "El procedimiento definitivo sería el que permitiera hacer arte automáticamente" (Aira 2021: 181). Los dos procedimientos implican la elisión del yo y la impersonalidad. No obstante, ¿qué es la automatización? ¿Qué significa hacer arte de manera automática? Para lograrlo, es necesario un aprendizaje del procedimiento. Butler hace el siguiente razonamiento: lo que 
hacemos perfectamente, es lo que hacemos automáticamente. De modo que la memoria absoluta coincide con el olvido: el músico que toca el violín (el ejemplo de Butler, no casualmente, es de arte, aunque su idea se aplica a cualquier acción de la vida, hasta la más elemental) lo hace de memoria, lo que significa que ha olvidado todo, porque lo ha incorporado todo. Es lo que Butler llama "hábito": una memoria tan perfecta que coincide con el olvido.

Esta concepción del arte es vitalista, es práctica y es física. Para Butler, la vida sobre el planeta es como una entidad compuesta de muchos órganos que son las especies, una suerte de monstruo. ¿No es acaso la imagen que muchos trabajos críticos dan de la obra de Aira? Incluso el motivo del monstruo está figurado en numerosas novelas (además de su ensayo sobre Arlt [2021: 137-163]) y las mismas ovejas encuentran, en una pampa que parece geológicamente antiquísima, los restos óseos de un animal desconocido:

Pero no mucho más allá, encontraron algo que las hizo detener: una osamenta, sobre el polvo. No supieron qué pensar. Rara vez iban por esos sitios, de manera que podía hacer muchos años que esos huesos estaban ahí, ignorados. [...] Parecían los de un animal grande, mucho más grande que una oveja. [...] Con sus mentes arqueológicas, se preguntaban por el ser animado que habría sido (1984: 119).

"La vida, entonces, es memoria", concluye Butler al final de su libro (2013: 244). Vivir es aprender, recordar y olvidar (es decir, tener una memoria absoluta, inconsciente), y en el individuo está la memoria de la especie. ${ }^{13}$ Esta imaginación genética podría ser lo que Las ovejas extraen de la concepción borgiana. La literatura, como un fenómeno que prescinde de los individuos, es parte de una misma gran actividad, que prescinde de todos los vivientes, y que es de la especie. Por fin, si, para Darwin, las especies evolucionan, en el sentido de que hay especies más aptas que otras, y que sobreviven por esa superioridad, Butler, en cambio, piensa, como Von Uexküll, que cada viviente es perfecto en sí mismo: la garrapata no es menos perfecta que el hombre europeo civilizado. ¿No es esta refutación del salto evolutivo coherente con la noción airiana de "literatura mala"? ¿No son todas sus novelas criaturas mutantes que no cuentan individualmente, siendo por separado "buenas" o "malas", sino que importan en la medida en que realizan la especie, que es la obra airiana?

Para Aira, la novela narra "lo que pasa" porque detrás de su definición está el surrealismo y la novela del siglo xx. Dice en su Copi: "Si nos atenemos a la primera definición que di (la novela es lo que pasa) los surrealistas escribieron

\footnotetext{
13 Dice Borges en "La postulación de la realidad": "En lo corporal, la inconciencia es una necesidad de los actos físicos. Nuestro cuerpo sabe articular este difícil párrafo, sabe tratar con escaleras, con nudos, con pasos a nivel, con ciudades, con ríos correntosos, con perros, sabe atravesar una calle sin que nos aniquile el tránsito, sabe engendrar, sabe respirar, sabe dormir, sabe tal vez matar: nuestro cuerpo, no nuestra inteligencia. Nuestro vivir es una serie de adaptaciones, vale decir una educación del olvido" (2007b: 255). Este "olvido" es la memoria perfecta. Desde el ejemplo del violín, Butler llega después hasta la locomoción, la respiración y la circulación, que son aprendizajes de la especie. Casualmente, en la cita de Borges volvemos a encontrarnos con un animal, esta vez con perros.
} 
las únicas novelas en estado puro, mutiladas de pasado, pura exposición de los acontecimientos del presente mental del autor" (1991a: 55). Este concepto de novela no le va mal a las ficciones de Borges, aunque haya renegado del género novelesco. ${ }^{14}$ Las ovejas es esta exposición puramente mental, que cuenta la genealogía de Borges en Aira, de un modo también borgiano, porque es la historia de la aventura mental de sus protagonistas, como en el soñador soñado de "Las ruinas circulares". Si la filosofía es la invención del hombre, como ser humano y como sujeto masculino, como obra de algunos individuos, la novela (la literatura, el arte, la poesía, el mito) es la alucinación colectiva de la especie, solo por historia masculina y solo por azar humana.

\section{OBRAS CITADAS}

Aira, César (2021). "Arlt", in La ola que lee, Ciudad Autónoma de Buenos Aires: Literatura Random House, 137-163

Aira, César (2021). "Ars narrativa", in La ola que lee, Ciudad Autónoma de Buenos Aires: Literatura Random House, 176-182.

Aira, César (2021). "Kafka, Duchamp", in La ola que lee, Ciudad Autónoma de Buenos Aires: Literatura Random House, 208-217.

Aira, César (2014). Continuación de ideas diversas. Santiago de Chile: Ediciones Universidad Diego Portales.

Aira, César (2015). "Quise escribir algo erótico", entrevista en Babelia, El País, 27 de julio. <https://elpais.com/cultura/2015/07/22/babelia/1437571976_587943.html> (1 de mayo de 2021).

Aira, César (1975). Moreira. Buenos Aires: Achával Solo.

Aira, César (1981). Ema, la cautiva. Buenos Aires: Editorial de Belgrano.

Aira, César (1984). El vestido rosa. Las ovejas. Buenos Aires: Ada Korn Editora.

Aira, César (1991a). Copi. Rosario: Beatriz Viterbo Editora.

Aira, César (1991b). Nouvelles impressions du Petit Maroc. Saint-Nazaire: Arcane 17.

Aira, César (1991c). La liebre. Buenos Aires: Emecé.

Aira, César (1993). "En el reino de las intenciones fallidas", entrevista con Guillermo Saavedra, in La curiosidad impertinente. Rosario, Beatriz Viterbo Editora, 133-140.

Aira, César (1995). "La innovación", Boletín del Centro de Estudios de Teoría y Crítica Literaria, 4: 27-33

Aira, César (2010). Yo era una mujer casada. Buenos Aires: Blatt \& Ríos.

Aira, César (2007). La vida nueva. Buenos Aires: Mansalva.

${ }^{14}$ Lo que permitiría despejar la incertidumbre de Remónd-Raillard cuando considera el architexto "novela" en un relato que intertextualiza a Borges: "L'etiquette de 'roman' mérite reflexion, puisqu'il s'agit d'un genre jamais abordé par Borges. Le texte réalise une sorte d'amalgame entre essai et fiction au moyen de l'intertextualité" ["La etiqueta de 'novela' merece reflexión, porque se trata de un género nunca abordado por Borges. El texto [Las ovejas] realiza una suerte de amalgama entre ensayo y ficción por medio de la intertextualidad"] (2003: 120). La afirmación pasa por alto el concepto idiosincrático de novela que maneja Aira y resuelve el problema conjeturando una "amalgama", con la que más arriba hemos disentido. 
Aira, César (2001). Un sueño realizado. Buenos Aires: Alfaguara.

Aira, César (2000a). El juego de los mundos. La Plata: Ediciones El Broche.

Aira, César (2000b). Un episodio en la vida del pintor viajero. Rosario: Beatriz Viterbo.

Aira, César (1999). "La cifra". Conferencia leída en Homenaje a Jorge Luis Borges en Alianza

Francesa de Buenos Aires. <https://revistaprause.blogspot.com/2019/10/la-cifracesar-aira.html> (1 de mayo de 2021).

Borges, Jorge Luis (2008). "Nueva refutación del tiempo", in Otras Inquisiciones. Obras Completas, tomo II. Buenos Aires: Emecé.

Borges, Jorge Luis (2007a). "Tlön, Uqbar, Orbis Tertius", "Funes, el memorioso", "El sur", in Ficciones. Obras Completas, tomo I. Buenos Aires: Emecé.

Borges, Jorge Luis (2007b). "La postulación de la realidad", in Discusión. Obras Completas, tomo I. Buenos Aires: Emecé.

Butler, Samuel (2013). Vida y hábito. La evolución más acá de la frontera entre lo natural y lo humano. Buenos Aires: Cáctus.

Contreras, Sandra (2013). Aira con Borges. Buenos Aires: La Biblioteca.

Contreras, Sandra (2002). Las vueltas de César Aira. Rosario: Beatriz Viterbo.

Contreras, Sandra (1995). "El movimiento de la idea", Boletín del Centro de Estudios de Teoría y Crítica Literaria, 4: 45-64.

Chávez Tortolero, Mario Edmundo (2016). "Sobre la imaginación y la fantasía en el pensamiento de Hume", in Imaginación y conocimiento. De Descartes a Freud, comp. Zuraya Monroy Nasr y Mauricio Rodríguez Salazar. México: Corinter-Gedisa, 51-62.

García, Mariano (2006). Degeneraciones textuales: los géneros en la obra de César Aira. Rosario: Beatriz Viterbo.

González, Darío (1993). "Alguien, algo, nadie (La imagen de Berkeley en la obra de Borges)", Paradoxa, 7: 31-37.

Gramuglio, María Teresa (1982). "Increíbles aventuras de una nieta de la cautiva", Punto de Vista, V.14: 27-28.

Gutiérrez, Eduardo (2011). Juan Moreira. Buenos Aires: Editorial Sol 90.

Kohan, Martín (1998). "Nación y modernización en Argentina: todo lo sólido se desvanece en Aira", in Poéticas argentinas del siglo xx, comp. Jorge Dubatti. Buenos Aires: Editorial de Belgrano, 161-173.

Koller, Sylvie (1990). "Le bestiaire de César Aira", Les Cahier du CRIAR, 11: 127-130.

Lamborghini, Osvaldo (2013). El fiord y Las hijas de Hegel, in Novelas y cuentos I. Buenos Aires: Mondadori.

Martin, Marina (2002). "Borges, perplejo defensor del idealismo", Variaciones Borges, 13: 7-21.

Martin, Marina (2000). "Via the dialectics of Berkeley and Hume", Variaciones Borges, 9: 147-162.

Montaldo, Graciela (1998). "Borges, Aira y la literatura para multitudes", Boletín del Centro de Estudios de Teoría y Crítica Literaria, 6: 7-17.

Oliveira, Eduardo Jorge de (2019). "Ficciones de la animalidad en América Latina. Las formas animales en la literatura y en las artes visuales", Pasavento. Revista de Estudios Hispánicos, 7.1: 79-96. 
Peller, Diego (2016). Pasiones teóricas. Crítica y literatura en los setenta. Buenos Aires: Santiago Arcos.

Piglia, Ricardo (1993). "Borges y los dos linajes", in La Argentina en pedazos. Buenos Aires: Ediciones de la Urraca.

Premat, Julio (2020). "Quehaceres espectrales. Pablo Katchadjian y la vanguardia hoy", Anclajes, XXIV.2: 1-16.

Podlubne, Judith (1996). "Cesar Aira: La lógica del continuo", Paradoxa, 8: 59-71.

Remónd-Raillard, Margarita (2003). "Pour une syntaxe totalisante. L'essai comme pré-texte et post-texte dans l'oeuvre de César Aira", Les Cahiers de I'ILCEA, 4: 119-132.

Rest, Jaime (2009). El laberinto del universo. Borges y el pensamiento nominalista. Buenos Aires: Eterna Cadencia.

Rodríguez, Fermín (2010). Un desierto para la nación. La escritura del vacío. Buenos Aires: Eterna Cadencia.

Saer, Juan José (2006). El río sin orillas. Tratado imaginario. Buenos Aires: Seix Barral.

Sarlo, Beatriz (2007). Escritos sobre literatura argentina. Buenos Aires: Siglo XXI.

Strafacce, Ricardo (2008). Osvaldo Lamborghini, una biografía. Buenos Aires: Mansalva.

Uexküll, Jakob Von (2016). Andanzas por los mundos circundantes de los hombres y los animales. Buenos Aires: Cactus. 